\title{
Using long-term investigations to develop silvicultural theory for new forestry
}

\author{
by E.D. Ford ${ }^{1}$
}

\section{Requirement For Silvicultural Theory}

Traditionally, silviculture has been a subject with a strong empirical knowledge base. Silviculturalists have successfully illustrated principles and practical procedures using field experiments and demonstrations of particular techniques. These have included fundamentals such as selection of tree species, establishment and tending, and thinning systems and their interaction with stand development. Many experiments and demonstrations have been maintained and analyzed for a decade or longer and in this respect long-term silvicultural research is not new.

What is new is the scope of silvicultural investigation. The objectives required for forests have broadened and these objectives are not secondary to timber production but central for forestry as a whole. The upsurge of interest in establishing new long-term research sites reflects concern that we do not have an existing empirical basis for creating silvicultures to meet these new objectives. The FERNS (Forest Ecosystem Research Network of Sites) network currently comprises fourteen sites distributed through six ecological zones of Canada. Reports on these sites at this workshop stress research to ensure biodiversity, sustainability, and aesthetic values, as well as timber yield and watershed management.

These new long-term experiments must help us design forests of the future. This is a sea change. Previous experimentation was conducted within a general framework of forest management for timber production and protection. Then, the primary objective of timber yield was clear and experiments were to show "how to" reach that objective (Table 1). Now that the requirement for timber yield no longer dictates the purpose and methods of forestry, some basic assumptions underlying research have changed. Silviculture no longer operates within the same predetermined framework. For example, attempts are underway to design forest systems that will simulate landscape patterns and stand structures produced by disturbance regimes, e.g., the Lake Duparquet Forest (Harvey 1999). In other cases the design requirement is forcibly expressed by the public and politicians alike, but using concepts, such as biodiversity, sustainability, amenity value, or aesthetic value, whose definitions are neither consistent between commentators nor constant over time. In these cases silviculturalists have frequently aimed to experiment with alternatives to clearcutting involving different spatial patterns and intensity of removal, e.g., the eastern white pine experiment (Burgess et al.1999). The question is whether these alternatives will meet the new objectives for management.

From the talks, posters, and discussions at the workshop I note three characteristics about investigations for designing new forest systems.

A. Other types of knowledge are required than those traditionally considered to be silviculture. Most importantly,

${ }^{1}$ College of Forest Resources, Box 352100, University of Washington, Seattle, Wa 98195 . we must find out how traditional silviculture may interact with this new knowledge. For instance, can knowledge about the efficiency of shelterwood systems on tree regeneration be related to its effects on wildlife?

B. The problems of forest design are diverse. Even within one forest type it is

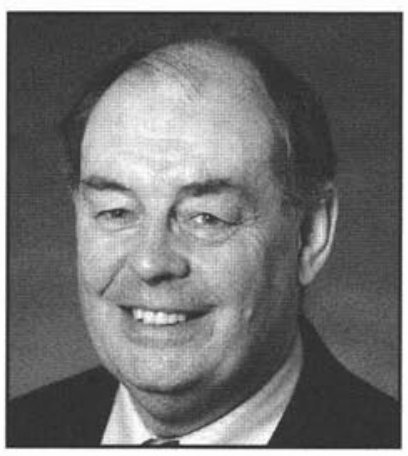
likely that different management objectives may be set for different areas. However, it is unlikely that multiple, extensive, long-term forest investigations can be established to provide empirical information for these different objectives in different areas.

C. Decisions on forest design must be made quickly - certainly we will not be allowed to wait for completion of long-term experiments. Rather we must use them as continuing guides for how silvicultural practices must change in response to environmental change, forest development, and the evolving needs of society.

From these characteristics I make three suggestions.

1. We are no longer building an empirical science. Of course, measurements and data-based investigations are central in research but we need to draw conclusions that can be used with other information to extrapolate and generalize. We will not be able to answer every question asked, or suggestion made, by reference to a specific experiment or demonstration.

2. We should not be satisfied with investigations seeking clearcut answers to simple questions. During the meeting both Dr. Powers (1999) and Dr. Franklin emphasized the value of experiments that used large differences between treatments - in particular, that statistically significant differences were more likely to be found. However, if the result of such a long-term experiment is simply "Yes, there is a difference between treatments!" then operational foresters will not be well pleased. Justifiably, they want answers to "How" and "Why" type questions for the design of new forest systems. Of course, they may not pose those questions precisely - that is our job as forest scientists.

3. Our central requirement is to take great care in analysis and synthesis. Analysis because we must plan any experimental treatments to provide a body of information that can answer diverse "How" and "Why" questions. Synthesis because we need to combine results and information from different types of research and be able to extrapolate to new situations with a defined uncertainty.

\section{What Is A Theory And How Can It Help?}

Taken together, these suggestions lead me to the conclusion that a principal requirement is to define new silvicultural theory. A theory has two parts: The working part of a theory 
Table. 1. The information required from silviculture investigations is changing from demonstrations of "how to" achieve specific goals within an established management framework to produce information on how to design complete forest systems

\begin{tabular}{ll}
$\begin{array}{l}\text { Type of experiment } \\
\text { or investigation }\end{array}$ & \multicolumn{1}{c}{$\begin{array}{c}\text { Required } \\
\text { information }\end{array}$} \\
\hline Establishment experiments & $\begin{array}{l}\text { "How to" information for different } \\
\text { species and cultural conditions } \\
\text { Choices of taking yield } \\
\text { Thinning experiments }\end{array}$ \\
$\begin{array}{l}\text { Provenance trials } \\
\begin{array}{l}\text { Experiments to simulate } \\
\text { "natural" forest patterns } \\
\text { of regeneration and scales } \\
\text { of stand sizes }\end{array}\end{array}$ & $\begin{array}{l}\text { Design of forest-landscape } \\
\text { interactions for visual amenity } \\
\text { and sustainable forest }\end{array}$ \\
$\begin{array}{l}\text { Experiments to integrate } \\
\text { obtaining timber production } \\
\text { with sustaining wildlife } \\
\text { visual amenity and other } \\
\text { objectives }\end{array}$ & Design of a forest system \\
\hline
\end{tabular}

provides the information and logical basis for making generalizations. It is represented as a logical construction comprising propositions, some of which contain established information (axioms) while others define questions (postulates). Theories also contain a motivational and/or speculative component that defines a general direction for investigation or type of question that can be answered. An over-arching axiom or postulate frequently specifies this component.

A theory defines what we know, the supporting information, and questions that may motivate the development of the theory or query its supporting evidence. (For further discussion of the definition and role of theory in research see Ford (1999).) Defining a theory is particularly important during analysis when investigations are being planned in areas of new research. In this respect current silvicultural research differs markedly from its tradition established over the last 50 years.

For example, if a new species is being introduced to a region, or managed for timber for the first time a thinning trial might be established. An assumption about management practice would be that stand density at establishment would be higher than at final harvest, competition between trees would occur, and thinning would be necessary to take yield during stand development and release large trees for continued growth. In most such cases there would be absolutely no need to specify competition theory in detail, nor the theory of how trees respond to release from thinning in crown development and cambial growth. Sufficient previous experiments have determined the type of results that will be obtained. The investigation would more likely be called a thinning trial than an experiment - with the objective of quantifying the yield parameters and providing information for advising on best practice for specific objectives.

As a contrast consider the EMEND project (Ecological Management by Emulating Natural Disturbance) in Alberta (Spence $e t a l^{2}$ ). Forest management there is adopting what the researchers refer to as the "natural disturbance" paradigm, mov-

\footnotetext{
${ }^{2}$ Spence, J. R., Pharo, E.J., Volney, W. J. A., MacDonald, S.E. and Cuthbertson, L. 1999. Ecological Management By Emulating Natural Disturbance (EMEND). Poster presentation at Long-term Silvicultural Research Sites: Promoting the Concept-Protecting the Investment Workshop, 25-28 October, 1998, Victoria, B.C.
}

ing away from extensive clearcutting and towards retention of unharvested residuals. The investigators state:

The overall ecological objective of the EMEND project is to determine which forest harvest and regenerative practices best maintain biotic communities, spatial patterns of forest structure, functional ecosystem integrity in comparison with landscapes that have originated through wildfire and other inherent natural disturbances.

These objectives are similar to those at many of the FERNS sites. In defining objectives for research the investigators of EMEND proposed on their poster at the workshop what they termed a central hypothesis: Recovery of ecosystem structure and function after partial harvesting is indistinguishable from patterns observed in the burned forest.

But in truth this is not a hypothesis. As it stands it can not be tested by measurement. Each of the terms used is a concept requiring detailed definition. Choices about these definitions and their associated measurements have to be made to translate this proposition into a testable hypothesis. Those choices depend upon definition of underlying theory and how it might apply in this situation. For example, ecosystem structure can mean many things from the relative numbers and biomass of primary producers, herbivores and carnivores to the degree of spatial heterogeneity of different vegetation components. More than one choice may be made and motivate different investigations - but any choice must be justified, not only in terms of the underlying ecological theory, but how it may be affected by the proposed silvicultural treatments. Both recovery and indistinguishable require definition that may vary according to definitions of ecosystem structure. Burned forest can have many different states.

It might be claimed that choice of definitions and consequent measurements would be obvious to the investigators who have local knowledge about the ecosystem. I reject that as sufficient. If we are to understand both strengths and weakness of alternative harvest systems the requirement is to explore alternatives in what we mean by these terms and how we measure them and not to accept any definition and measurement procedures uncritically. Of course, this is also essential politically. In today's climate of vigorous debate over the future of forests, any reduced set of measurements may seem to imply that the experiments themselves have been planned with a particular purpose in mind for forestry.

In practice, then, the definition and development of silvicultural theory becomes central in the progress of this new science (Fig. 1). Our current questions are simply too large and too amorphous for us to expect to obtain simple answers from "clear cut" experiments. We can expect to synthesize results from many different types of investigations.

A number of speakers mentioned the importance of having a vision in establishing long-term investigations. Dr. Ted Wilson (Wilson et al. 1999) described the vision of Professor M.L. Anderson of Edinburgh University who, surrounded by the seemingly inexorable progress of monoculture in the United Kingdom, nevertheless established experiments in multiple-species forest development. The vision was expressed in these experiments, but Anderson also wrote some parts, for example in his Selection of Tree Species (Anderson 1950). The essential value of visions is that they illustrate that there may be a way forward. The difficulty with visions is that they contain undefined assumptions and incompletely specified ques- 


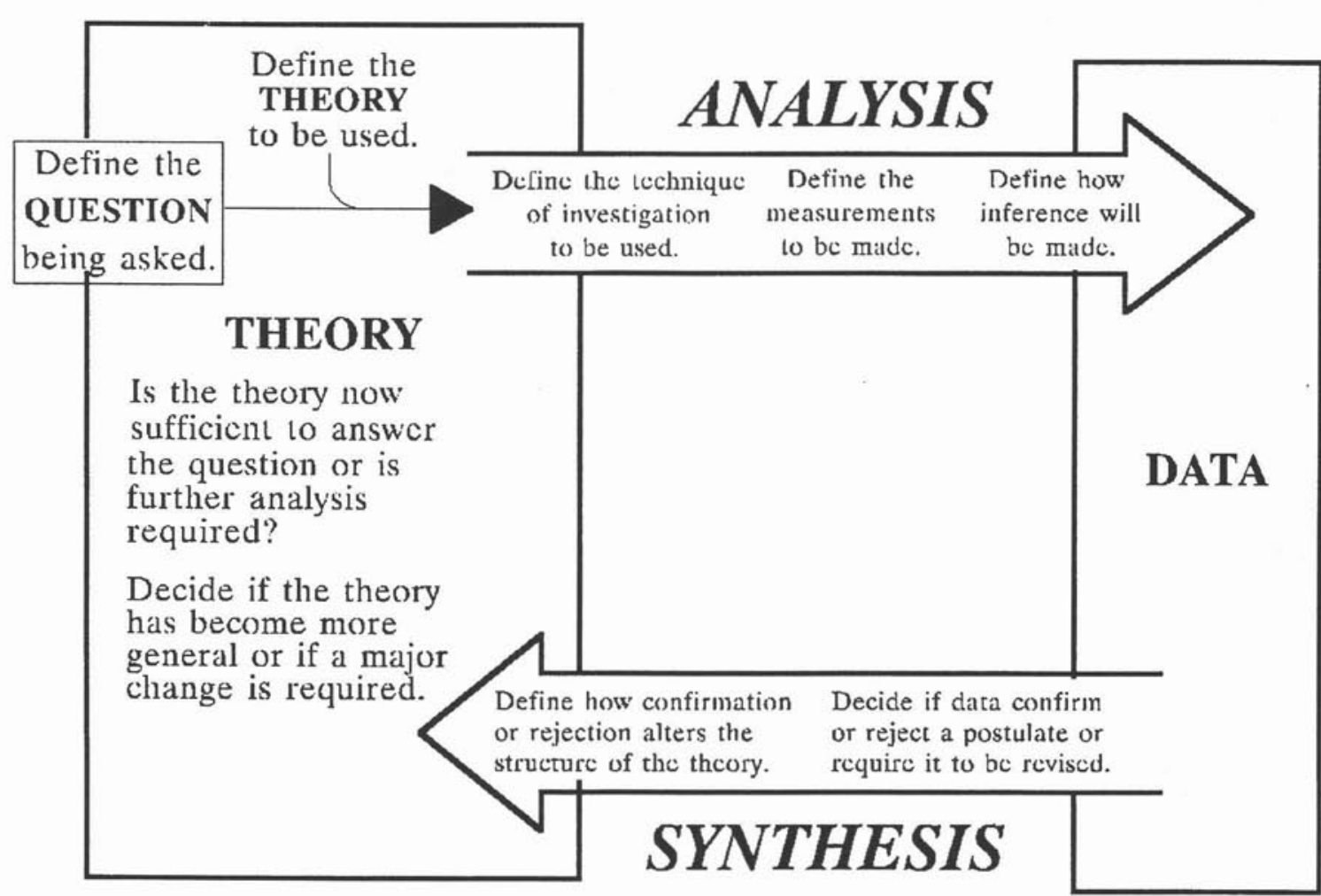

Fig. 1. Diagrammatic representation of the interaction between empirical investigation, requiring analysis of question and relevant theory before it can proceed, and theory development, requiring continued synthesis of new results with theory. (Adapted from Ford (1999).)

tions. Clarifying these assumptions and questions is essential for developing and implementing new procedures to refine and implement the vision.

Meeting new design objectives requires analysis and synthesis from different bodies of knowledge, such as silvicultural systems, population ecology, ecosystem processes, and landscape ecology. It is important that this synthesis be explicit and not allow the dominance of one body of knowledge, either because of its appeal to popular taste or because it uses a sparkling new technology. Each body of knowledge has its own methodological difficulties. Ecology still has difficulty in making the transition from specific investigations to generalizations that compose an accepted theory. Silviculture has general theories, as expressed in textbooks by Toumey (1947), Assmann (1970), Smith (1986), and Nyland (1996) that are used, often implicitly, in creating empirical trials. But the theory does not cover the new problems. Landscape ecology is still a new subject. It is related to, but not yet fully integrated with, the practical art of landscape design and that incompleteness may cause difficulty.

A theory can be written down, leading to communication, criticism and scientific progress. It is essential for those involved with these new investigations to be explicit about the theory they develop. If they are not there is the possibility of being buffeted by the enthusiasms and sidetracked by the incompleteness of neighbouring and contributing subjects.

\section{Some Problems Of Analysis And Design}

The most disruptive confusion in ecological research methodology is due to multiple use of the word hypothesis (Fig. 2). The specification of an overarching postulate of the type given by the EMEND project is essential. But it is a postulate, not a testable hypothesis, and failure to recognize that detailed conceptual and propositional analysis is essential before practical work can be developed leads to difficulties. Sometimes the choice of measurements is arbitrary, or is simply what an investigator can afford or has an instrument for. Such decisions, if made without detailed analysis, disconnects the actual hypothesis to be tested from the postulate under consideration.

Where new measurements are being made it is important to conduct exploratory analysis to determine the power that any investigation has. Premature hypothesis testing can lead to Type II errors. What concerns me about Dr. Powers' and Dr. Franklin's recommendation for large differences between experimental treatments is that they can be used to ensure a "significant difference" in the experiment in terms of basic statistics but at the cost of sacrificing the full potential of the research (Powers 1999).

Consider testing for differences in a sampled quantity between treatments in a long-term experiment, using as an example, a $t$-test. The width of confidence interval for a $t$-test with $s=1$ and increasing values of $n$ is given by Fig. 3. Four things control the width of the confidence interval and whether a difference between treatments will be detected.

1. The forest and its environment determine $s$. This can be influenced by where an experiment is located.

2. The investigator chooses the level of significance, ( (or follows a convention).

3. The investigator chooses $n$, the number of observations, most usually three in the long-term experiments, and so confidence intervals are typically wide (Fig. 3). 


\section{Three meanings of the word hypothesis.}

A set of propositions

set out as an explanation.
A conjecture, a new

or unexplored idea.
A statement that will be tested by investigation.

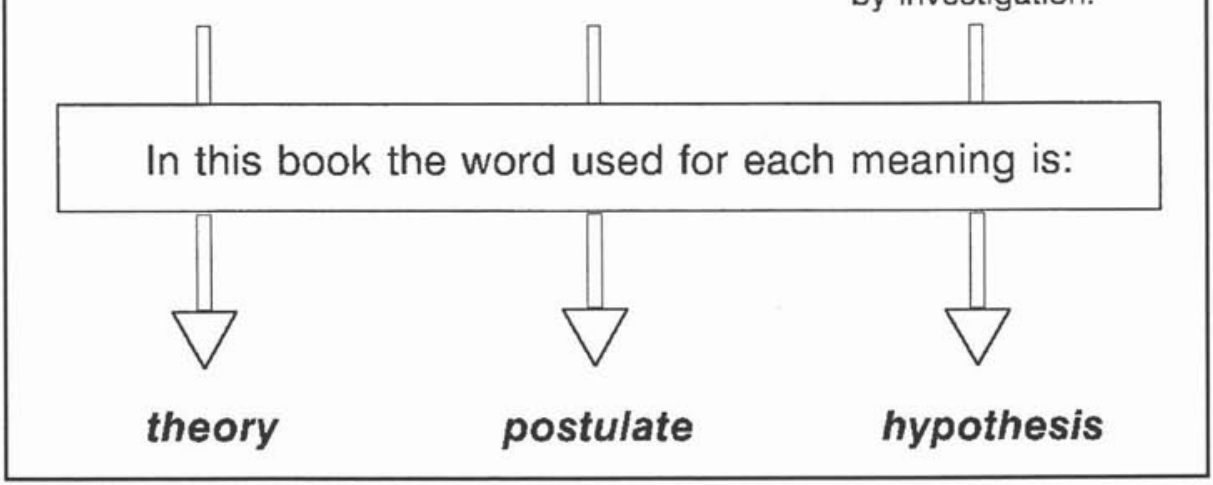

Fig. 2. Multiple meanings given to hypothesis lead to confusion in analysis of scientific problems. Each meaning represents a distinct and important component in the development of scientific inquiry. It is essential to recognize the process of analysis and practical investigation required to move between them otherwise assumptions remain undefined and postulates are incompletely specified.
4. Choosing large differences between experimental treatments is a way around the problem of obtaining wide confidence intervals due to small sample size. But, frankly, this could be just part of the game we play to obtain a "significant difference" in the conventional way and so, we think, ensure publication of results!

It is important to choose treatments that examine alternatives, e.g., clumped retention versus dispersed retention. And it is important not to confound treatments, e.g., to compare differences of different patterns of retention at the same intensity of removal. But it is also important to choose treatments that will provide information on the "Why" (i.e., why use different treatments) and "How" (i.e., how to attain them) of future silvicultures. The true significance of treatments will come from investigations that explain "Why" and "How" the results obtained were, or were not, different. The investigations Dr. Powers reports (1999) give a strong indication of the importance of focussed ancillary investigations and of having largesized replicates so that these can take place.

The standard statistical analysis techniques of $t$-tests and ANOVA are unlikely to be suitable for the analysis of differences between treatments in long-term experiments. ANOVA assumes homogeneity of variance and, while that has been found a reasonable assumption for agricultural field trials, it is much less likely to be so for experiments in natural or seminatural forest. The ANOVA statistics for detecting that there is a difference between treatments is robust against deviation from this assumption, but it is not robust for making comparisons between component treatments. It would not be a happy position to be in, if by restricting our conclusions to only those shown significant in ANOVA we say, "Yes, there is a difference between the treatments we used - but we can not really say what it is!"

In practice, once the treatments required by the silvicultural questions have been specified then it is essential to study both spatial and temporal variation of responses within replicates and to treat their analysis in a responsible way biometrically. Dr. Rich Fleming gives an essential introduction to some important biometrical considerations for these problems (Fleming 1999). Because of the likely complexity of response it could be dangerous to embark on a long-term experiment without persuading a biometrician to be involved in detail with what

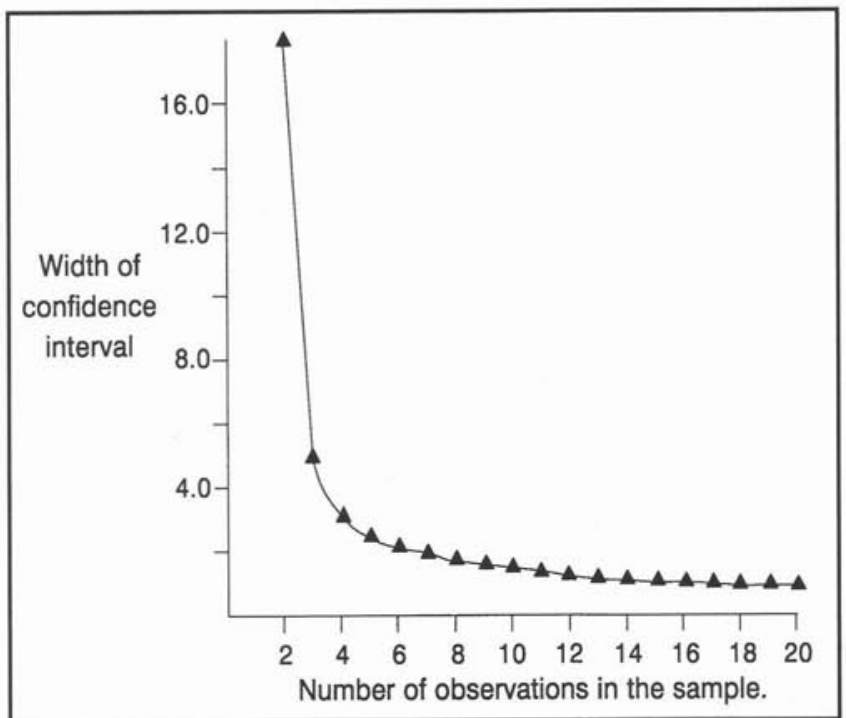

Fig. 3. Width of the confidence interval $2 \mathrm{t}_{0.025} \mathrm{~s} /(\mathrm{n}$ for increasing values of $n$ with $s=1$.

you intend to do. The biometrician should understand the importance of power and robustness for the experiment and have an interest in problems of spatial analysis and modelling the short time series likely to be available from these experiments by the time you are expected to make some recommendations.

\section{Some Problems of Synthesis?}

Synthesis is a process that must not be left to the end of an experiment but must proceed as the work does. Unfortunately, it was not mentioned in any of the talks I attended and only one questioner asked about the process. Of course, when establishing a long-term experiment one's mind is occupied with a thousand and one details and synthesis is easily pushed aside to be considered "later." However, long-term experiments can produce unexpected results and the capacity to recognize and react to them can make the difference between success and failure. This requires continuing synthesis of results.

Furthermore, synthesis must not be delegated to some third party (modelers have been favourite candidates in eco- 
logical investigations and they have rarely succeeded in that task). Silvicultural experiments have the tremendous advantage over long-term ecological investigations such as conducted in the U.S. LTER system (Franklin, personal communication) because they do have direct questions which, providing they have been effectively analyzed, can provide a focus around which a synthesis can be built.

\section{Summary And Conclusion}

There is a danger that we may look on long-term silvicultural investigations simply as extensions of the long tradition of empirical research in silviculture as exemplified by thinning experiments and species and establishment trials. This would be a mistake if it led to the expectation that long-term investigations would provide "simple answers to straightforward questions." The questions faced in forest design are not simple and, without over-complication, it falls to the silviculturalist to analyze and explain the comprehensive range of issues involved - both in the ecology and in the management choices.

I think this is important for silviculturalists as a profession. They have to explain the comprehensive nature of what must be investigated, and why it is needed, in public and policy forums. A more extensive synthesis is required of what comprises silvicultural knowledge than we have been used to in the past. If silviculturalists do not do this then some other group of professionals will.

\section{References}

Anderson, M.L. 1950. Selection of Tree Species. Oliver and Boyd, Edinburgh. $151 \mathrm{p}$.

Assmann, E. 1970. The Principles of Forest Yield Study. Pergamon, Oxford. 506p.

Burgess, D., S. Wetzel, and F. Pinto. 1999. Regenerating eastern white pine: A cooperative research approach. For. Chron. 75(3): 423-425. Fleming, R. A. 1999. Statistical advantages in, and characteristics of, data from long-term research. For. Chron. 75(3): 487-489.

Ford, E.D. 1999. Scientific Method for Ecological Research. Cambridge University Press, Cambridge, U.K. (in press).

Harvey, B. D. 1999. The Lake Duparquet Research and Teaching Forest: Building a foundation for forest ecosystem management. For. Chron. 75(3): 389-393.

Nyland, R.D. 1996. Silviculture: Concepts and Application. McGrawHill, New York. 663 p.

Powers, R. F. 1999. If you build it, will they come? Survival skills for silvicultural studies. For. Chron. 75(3): 367-373.

Smith, D. M. 1986. The Practice of Silviculture. Wiley, New York. $527 \mathrm{p}$.

Toumey, J.W. 1947. Foundations of Silviculture upon an Ecological Basis. 2nd Edition. Wiley, New York. 468 p.

Wilson, E.R., H. Whitney McIver and D.C. Malcolm. Transformation to irregular structure of an upland conifer forest. For. Chron. 75(3): 407-412. 